\title{
Efficacy and Safety Outcomes of Catheter Ablation of Non-valvular Atrial Fibrillation in Korean Practice: Analysis of Nationwide Claims Data
}

Gi-Hyeon Seo'; Sung-Won Jang, MD, $\mathrm{PhD}^{2}$; Yong-Seog Oh, MD, PhD2; Man Young Lee, MD, $\mathrm{PhD}^{2}$;Tai-Ho Rho, MD, PhD2

${ }^{1}$ Health Insurance Review and Assessment Service, Seoul, Korea

${ }^{2}$ Division of Cardiology, Department of Internal Medicine, College of Medicine, The Catholic University of Korea, Seoul, Korea
Received: January 17, 2018

Accepted: March 22, 2018

Correspondence: Sung-Won Jang, MD, PhD

St. Paul's Hospital, 180 Wangsan-ro Dongdaemun-

gu, Seoul, 02559, Korea

Tel: +82-2-961-4508 FAX: +82-2-968-7250

E-mail: sungwon.jang@catholic.ac.kr

Copyright (C 2018 The Official Journal of Korean Heart Rhythm Society Editorial Board

\begin{abstract}
Background and Objectives: The aim of this study was to investigate the effectiveness and selected adverse events of radiofrequency catheter ablation in patients treated for drug-refractory atrial fibrillation (AF) using claims data provided by the Health Insurance Review and Assessment Service, which covers all ablation procedures conducted in South Korea.
\end{abstract}

Subjects and Methods: The study population included patients who underwent catheter ablation for AF between January 2011 and December 2013. A total of 3,850 patients without a previous history of catheter ablation procedure were enrolled. We analyzed 2-year effectiveness of the index ablation. Any redo ablation, electrical cardioversion, or use of antiarrhythmic drug beyond the blanking period of 3 months was considered a failure of index ablation.

Results: Overall recurrence rate following AF ablation was $61.1 \%$. The recurrence rate was lower in patients under 65 years old than in those over 65 years old (hazard ratio [HR] 0.89; 95\% confidence interval [Cl], 0.81 to $0.97, P=0.009)$. Repeat ablation was more frequent in men (HR 1.56; 95\% Cl, 1.20 to $2.04 ; P=0.001)$ and patients under 65 years old (HR 1.79; 95\% Cl, 1.34 to $2.38 ; P<0.001$ ). Electric cardioversion was more frequent in men $(\mathrm{HR} 1.35 ; 95 \% \mathrm{Cl}, 1.06$ to $1.72 ; P=0.014$ ) than in women. The overall rate of stroke, blood transfusion, significant pericardial complication, and cardiopulmonary resuscitation was $0.5 \%, 4.8 \%, 2.7 \%$, and $0.2 \%$, respectively.

Conclusions: In the present study, old age was associated with treatment failure of catheter ablation for drug-refractory AF in the Korean population. Overall recurrence did not vary with respect to sex.

Key Words: - Atrial Fibrillation -Catheter Ablation - Recurrence -Pericardiocentesis -Hemorrhage -Blood Transfusion -Stroke 


\section{Introduction}

Percutaneous catheter ablation has emerged as a potentially curative interventional tool for rhythm control in patients with atrial fibrillation (AF). ${ }^{1}$ In selected patients, radiofrequency catheter ablation has been demonstrated as superior to current antiarrhythmic drug therapy in maintaining sinus rhythm, symptom relief, and preventing hospitalization. ${ }^{2}$ However, both clinical trials and observational studies have shown that there is remarkable variance with respect to effectiveness outcomes. This variance could be related to several factors including different ablation techniques, varying experiences across hospitals, definition of success and relapse, and patient selection.

We aimed to investigate the effectiveness and selected adverse events of radiofrequency catheter ablation in patients treated for drug-refractory AF between January 2011 and December 2013 using claims data provided by the Health Insurance Review and Assessment Service (HIRA), which covers all ablation procedures conducted in South Korea.

\section{Subjects and Methods}

\section{Data source}

Data were retrieved from the HIRA database, which contains population and reimbursement data from the national health insurance service. The HIRA database includes diagnosis (International Classification of Disease, $10^{\text {th }}$ revision [ICD-10]), procedure records, prescription records (drug name, formula, dose, and duration of prescription), and demographic information. ${ }^{3}$

\section{Study Population}

The study population included patients who underwent catheter ablation (M6542) for AF between January 1, 2011 and December 31, 2013. Only patients with no previous history of catheter ablation procedure were included, so that the ablation of interest was the first procedure in a given patient and was considered the index ablation. Patients who underwent catheter ablation for any atrial arrhythmia before the index procedure were also excluded. Thus, a total of 3,850 patients were enrolled (Figure 1). Admission codes were not analyzed because we considered that admission would be mandatory for AF ablation in South Korea.

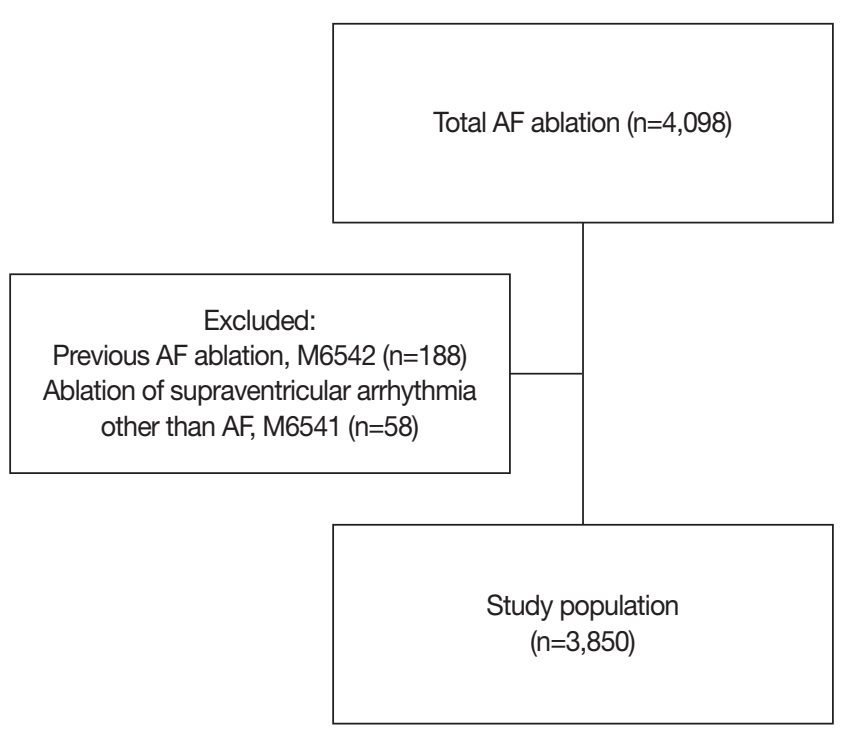

$<$ Figure 1. Flow Chart >

The HIRA database does not contain clinical data. Types of AF, such as paroxysmal, persistent, or permanent, and duration of AF cannot be discriminated. For catheter ablation to be reimbursed by healthcare insurance in South Korea, patients should have received antiarrhythmic drug treatment for at least 6 weeks. In addition, pulmonary vein isolation using cryoballoon is not reimbursed. Therefore, AF ablation as a first-line treatment (without previous medical treatment) and cryoballoon ablation procedures are not included in the present study. Surgical ablation cases were also excluded.

\section{Outcomes}

The 2-year effectiveness of index ablation was estimated. Any redo ablation of AF (M6542, M6547), supraventricular arrhythmias (M6541, M6546), or electrical cardioversion (M5880) beyond the blanking period of 3 months was considered a failure of index ablation. Redo ablation of supraventricular arrhythmias under the diagnosis of paroxysmal supraventricular tachycardia (I470) was not counted as an ablation failure. It was 
also considered a failure if a patient used an antiarrhythmic drug beyond 3 months after the index ablation procedure, regardless of whether the prescription was consecutive or intermittent. Patients were considered to have followed a given drug treatment when they received at least one delivery of the drug. The blanking period of 3 months was accounted for and represents the time required for the ablation scar to heal. Redo ablation, electrical cardioversion, or the use of antiarrhythmic drugs during this period was not considered failed ablation.

Antiarrhythmic drug use before and after the index ablation was analyzed. Antiarrhythmic drugs available in South Korea include flecainide, pilsicainide, and propafenone for Vaughan Williams class Ic drugs, and amiodarone, dronedarone, and sotalol for class III drugs. Beta blockers and calcium channel antagonists were not regarded as antiarrhythmic drugs. Anticoagulants including warfarin, dabigatran, rivaroxaban, and apixaban were analyzed. Edoxaban was not approved by the Ministry of Drug and Food Safety during the study period.

Selected codes that were claimed during admission for index ablation were retrieved for safety analysis. The following are considered significant complications of catheter ablation: stroke (I60-I64), any use of red blood cell product or autotransfusion after ablation procedure (X1001, X1002, X2021, X2022, X2031, X2032, X2091, X2092, X2111, X2112, X6001, X6002, X6006), pericardiocentesis (C8060), creation of pericardial window by surgical approach (O1932, O1935), cardiopulmonary resuscitation (M5873-7), and death during the admission period.

\section{Statistical Analysis}

Continuous variables were expressed as mean \pm standard deviation (SD) and and compared using an unpaired Student's t-test. Categorical variables were expressed as number (percentage) and compared using a chi-square test or Fisher's exact test, where appropriate. All comparisons were two-sided, and $P$ values $<0.05$ were regarded as statistically significant. A number of events defined as recurrence were introduced in a Kaplan-Meier time-to-event analysis. Hazard ratio and confidence intervals were estimated using the Cox regression model. All statistical analyses were performed using R program 3.2.2.

\section{Results}

Baseline characteristics are summarized in Table 1. Mean age was $57.0( \pm 10.8)$ years and $73.3 \%$ of patients were male. Effectiveness outcomes are summarized in Table 2. Overall recurrence rate following $\mathrm{AF}$ ablation was $61.1 \%$. Repeat ablation was more frequent in men and patients under 65 years old than in women and patients over 65 years old, respectively. Electric cardioversion was more frequent in men than women, but age was not a discriminating factor for electric cardioversion. However, the rate of antiarrhythmic drug use after the blanking period was significantly lower in patients under 65 years old than in those over 65 years old. Overall analysis showed that recurrence rate was lower in patients under 65 years old than in those over 65 years old, but it did not vary between men and women. Event-free survival is shown in Figure 2. While repeat ablation and electric cardioversion occurred steadily after the blanking period, use of antiarrhythmic drugs was concentrated between 3 and 6 months.

\section{Table 1. Baseline characteristics}

\begin{tabular}{ll}
\hline Characteristics & \\
\hline Age, mean (SD), y & $57.0(10.8)$ \\
Age group, $\mathrm{n}(\%)$ & \\
$<40$ & $225(5.8 \%)$ \\
$40-49$ & $650(16.9 \%)$ \\
$50-59$ & $1,355(35.2 \%)$ \\
$60-69$ & $1,147(29.8 \%)$ \\
$\geq 70$ & $473(12.3 \%)$ \\
Male, $n(\%)$ & $2,821(73.3 \%)$ \\
Total, $n(\%)$ & $3,850(100.0 \%)$ \\
\hline
\end{tabular}

$\mathrm{SD}$, standard deviation

Anticoagulants were used in 2,006 patients (52.1\%) at 2 years after index ablation procedures. Vitamin-K antagonists, dabigatran, rivaroxaban, and apixaban were used in 1,948 (97.2\%), 28 (1.4\%), 25 (1.2\%), and 5 patients (0.2\%), respectively. Table 3 summarizes use of antiarrhythmic drugs around index ablation. Before index ablation, frequently used drugs included 
Table 2. Effectiveness outcomes

\begin{tabular}{|c|c|c|c|c|c|c|c|}
\hline \multirow[b]{2}{*}{ Efficacy outcomes } & \multirow{2}{*}{$\begin{array}{c}\text { Overall } \\
(n=3.860)\end{array}$} & \multicolumn{3}{|c|}{ Gender } & \multicolumn{3}{|c|}{ Age } \\
\hline & & $\begin{array}{c}\text { Male } \\
(n=2.821)\end{array}$ & $\begin{array}{l}\text { Female } \\
(n=1,029)\end{array}$ & $\begin{array}{l}\text { HR }(95 \% \text { CI) } \\
\text { Male vs. female }\end{array}$ & $\begin{array}{l}<65 \text { years } \\
(n=2.866\end{array}$ & $\begin{array}{c}\geq 65 \text { years } \\
(n=984)\end{array}$ & $\begin{array}{l}\mathrm{HR}(95 \% \mathrm{Cl}) \\
<65 \text { vs. } \geq 65\end{array}$ \\
\hline Repeat ablation, n(\%) & $346(9.0)$ & $279(9.9)$ & $67(6.5)$ & $\begin{array}{c}1.56(1.20-2.04) \\
P=0.001\end{array}$ & $290(10.1)$ & $56(5.7)$ & $\begin{array}{c}1.97(1.34-2.38) \\
P<0.001\end{array}$ \\
\hline Electric cardioversion, n(\%) & $392(10.2)$ & $307(10.9)$ & $85(8.3)$ & $\begin{array}{c}1.35(1.06-1.72) \\
P=0.014\end{array}$ & 279(9.7) & $113(11.5)$ & $\begin{array}{c}0.82(0.66-1.03) \\
P=0.084\end{array}$ \\
\hline Use of AAD, n(\%) & $2,329(60.5)$ & $1,706(60.5)$ & $623(60.5)$ & $\begin{array}{c}1.02(0.93-1.12) \\
P=0.640\end{array}$ & $1,708(59.6)$ & $621(63.1)$ & $\begin{array}{c}0.88(0.80-0.97) \\
P=0.007\end{array}$ \\
\hline Any of the above outcomes, n(\%) & $2,352(61.1)$ & $1,721(61.0)$ & $631(61.3)$ & $\begin{array}{c}1.02(0.93-1.11) \\
P=0.706\end{array}$ & $1,727(60.3)$ & $625(63.5)$ & $\begin{array}{c}0.89(0.81-0.97) ; \\
P=0.009\end{array}$ \\
\hline
\end{tabular}

$H R$, hazard ratio; $C l$, confidence interval; $A A D$, anti-arrhythmic drug

Free from repeat ablation
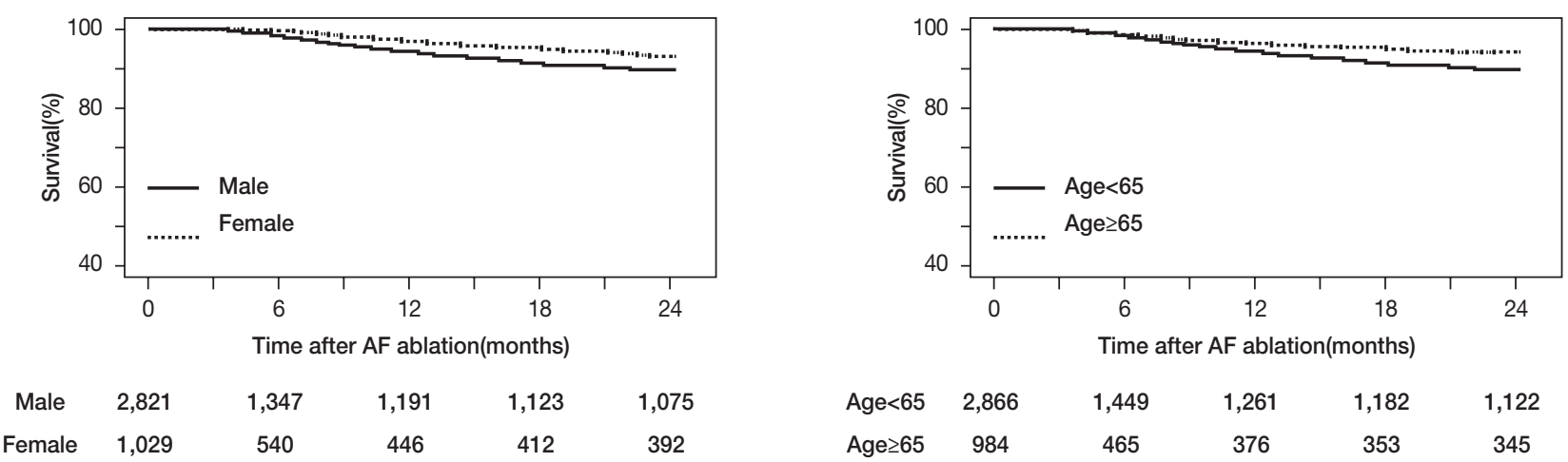

Free from electric cardioversion
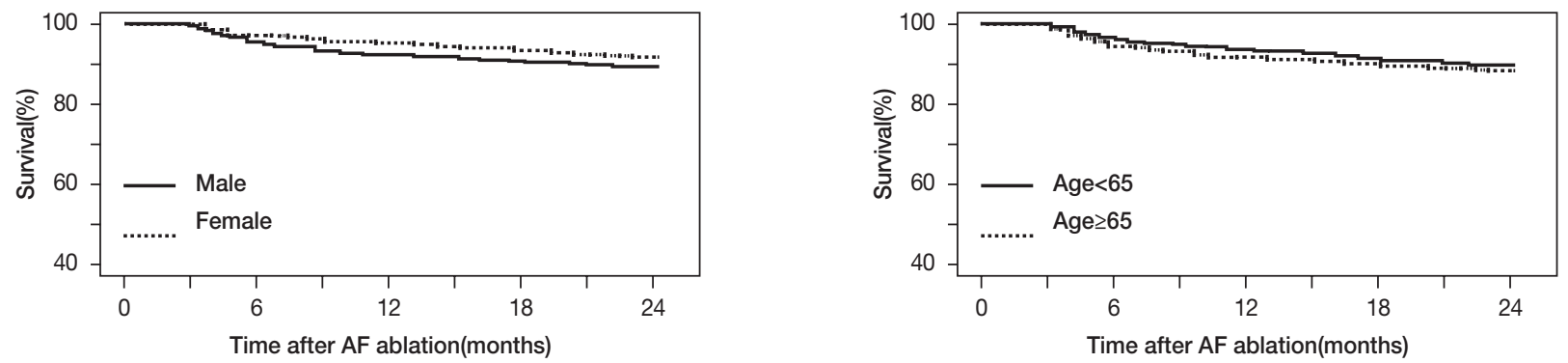

Free from antiarrhythmic drug
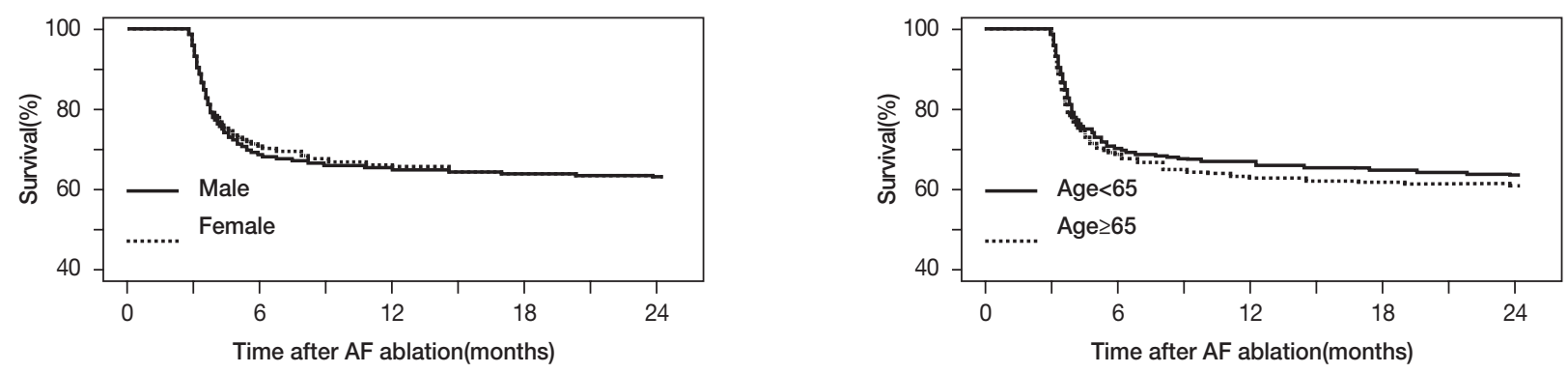

Figure 3. Kaplan-Meier curve of event free survival 
Table 3. Use of antiarrhythmic drugs before and after index procedure

\begin{tabular}{lcccc} 
& \multicolumn{2}{c}{ Before index ablation } & \multicolumn{2}{c}{ Two-year follow-up } \\
\hline Amiodarone & $\mathrm{n}$ & $\%$ & $\mathrm{n}$ & $\%$ \\
Dronedarone & 1,589 & $41.3 \%$ & 1,057 & $27.5 \%$ \\
Flecainide & 32 & $0.8 \%$ & 129 & $3.4 \%$ \\
Pilsicainide & 1,956 & $50.8 \%$ & 1,062 & $27.6 \%$ \\
Propafenone & 781 & $20.3 \%$ & 259 & $6.7 \%$ \\
Sotalol & 1,973 & $51.2 \%$ & 524 & $13.6 \%$ \\
Total AAD & 268 & $7.0 \%$ & 198 & $5.1 \%$ \\
\hline
\end{tabular}

$A A D$, antiarrhythmic drug

Table 4. Safety outcomes

\begin{tabular}{lccc} 
& $\begin{array}{c}\text { Male } \\
(\mathrm{n}=2,821)\end{array}$ & $\begin{array}{c}\text { Female } \\
(\mathrm{n}=1,029)\end{array}$ & $\begin{array}{c}\text { Total } \\
(\mathrm{n}=3,850)\end{array}$ \\
\hline Stroke, $\mathrm{n}(\%)$ & $12(0.4)$ & $6(0.6)$ & $18(0.5)$ \\
Blood transfusion, $\mathrm{n}(\%)$ & $89(3.2)$ & $96(9.3)^{\star}$ & $185(4.8)$ \\
Pericardiocentesis, $\mathrm{n}(\%)$ & $77(2.7)$ & $28(2.7)$ & $105(2.7)$ \\
Creation of pericardial window & 1 & 0 & 1 \\
Cardiopulmonary resuscitation, $\mathrm{n}(\%)$ & $4(0.1)$ & $2(0.2)$ & $6(0.2)$ \\
Death during admission & 2 & 1 & 3 \\
Any of the above outcomes, $\mathrm{n}(\%)$ & $138(4.9)$ & $112(10.9)^{\star}$ & $250(6.5)$ \\
\hline
\end{tabular}

${ }^{*} P<0.001$

flecainide, propafenone, and amiodarone. Flecainide and amiodarone were common after the index ablation. Table 4 summarizes safety outcomes. Among those who underwent pericardiocentesis ( $\mathrm{n}=105), 55$ patients were also given a blood transfusion (42 males, 15 females). Only 1 patient underwent surgery for a pericardial window instead of pericardiocentesis. Cardiopulmonary resuscitation was performed in 6 patients.

\section{Discussion}

Catheter ablation for $\mathrm{AF}$ is more effective than antiarrhythmic drug therapy in restoring and maintaining sinus rhythm. ${ }^{4}$ In general, it is used as a second-line treatment after failure of or intolerance to antiarrhythmic drug therapy. As first-line treatment, randomized clinical trials have demonstrated that catheter ablation reduce the episodes of atrial arrhythmia ${ }^{5}$ and the burden of symptomatic AF. ${ }^{6} \mathrm{~A}$ meta-analysis also showed similar effectiveness benefit ${ }^{7}$ and current guidelines recommend the use of catheter ablation as first-line treatment in selected patients. ${ }^{1,2}$

\section{Effectiveness analysis}

The success rate of catheter ablation in patients with $\mathrm{AF}$ is quite variable. Reasons for variable success rates include differences in patient characteristics, AF status, ablation technique or method, definition of procedural success, and follow-up period. 
As expected, there is more recurrence with a longer follow-up period. A meta-analysis of 11 studies comprising 1,481 participants revealed 28\% recurrence of atrial tachyarrhythmia with a follow-up of about 1 year. ${ }^{7}$ The long-term (2 years or more) success rate of a single procedure, defined as the percentage of patients free of atrial arrhythmia at latest follow-up, was $53.1 \%$ in another meta-analysis of 19 clinical trials. ${ }^{8}$ Longer-term follow-up data were more disappointing. In a small set of 139 patients, freedom from atrial arrhythmias was $27.9 \%$ in the ablation group and $4.3 \%$ in the antiarrhythmic drug therapy group over a 12-year follow-up. Although catheter ablation was significantly superior to drug therapy, sinus rhythm was maintained in fewer than one-third.

Variable ablation techniques are used for a wide range of AF status. Complete pulmonary vein isolation on an atrial level is the standard target for catheter ablation. ${ }^{10,11}$ More extensive lesions such as linear lesions and complex fractionated atrial electrograms have been used in patients with persistent AF, but there are insufficient data to recommend this addition as a routine procedure. $^{12-14}$

Randomized controlled trials use a variety of definitions of procedural success including freedom from symptomatic AF, freedom from symptomatic and asymptomatic episodes of AF, $>90 \%$ reduction of $\mathrm{AF}$ burden, and proportion of patients free from $\mathrm{AF}$ in a given period of time or on electrocardiography (ECG) or Holter monitoring. ${ }^{15}$ Available methods for arrhythmia monitoring include scheduled or symptom-initiated standard ECGs, Holter monitoring (24 hours to 7 days), transtelephonic recording, patient- and automatically-activated device, and implantable loop recorder. The likelihood of detecting AF is directly dependent on the duration and intensity of arrhythmia monitoring during follow-up. Recurrence of AF after ablation is defined as AF recurrence more than 3 months following AF ablation. ${ }^{15}$

In our study, recurrence of AF ablation was defined as repeat catheter ablation, electrical cardioversion, and antiarrhythmic drug use after a blanking period of 3 months. Most clinical trials use ECG-based recordings to define AF recurrence, but studies analyzing claims data use the same definition as ours because ECG data cannot be examined. The recurrence rate following AF ablation was $61.1 \%$ in the present study. Since reimbursement for AF ablation in South Korea is restricted to drug refractory AF, all subjects in our study undertook catheter ablation as a second-line treatment. Whether the AF is paroxysmal or persistent cannot be discriminated. In a study using the Belgian nationwide healthcare database, AF recurred in $49.9 \%$ of patients after 2 years. ${ }^{16}$ Their definition of AF recurrence is the same as ours except for antiarrhythmic drug use. They counted antiarrhythmic drug use as a failure only if the drug was delivered for over 21 months beyond a 3-month blanking period. Meta-analysis of clinical trials with a mean follow-up of at least 24 months reported $53.1 \%$ freedom from atrial arrhythmia after a single-procedure. ${ }^{8}$ The results of healthcare claims data are in line with these clinical trials.

Predictors of AF recurrence following catheter ablation include long-standing persistent AF, sleep apnea and obesity, increased left atrial size, increased age, hypertension, and left atrial fibrosis detected by cardiac MRI. ${ }^{17-19}$ Age and sex as independent predictors for AF recurrence remain controversial. In one study including 258 consecutive patients, Cox regression analysis demonstrated age (HR, 1.307; CI, 1.081-1.580) and female sex (HR, 1.460; CI, 1.017-2.097) to be independent predictors for recurrence of AF after first catheter ablation..$^{20}$ However, other studies demonstrated that recurrence was not associated with sex and age. ${ }^{19,21}$ In the present study, patients under 65 years old had a significantly lower recurrence rate than those over 65 years old. Overall recurrence did not vary with respect to sex. Interestingly, male patients and patients under 65 years old showed significantly higher rates of repeat ablation. Considering that male patients constitute $73.3 \%$ of index procedures, males are more likely to prefer invasive treatment than females in South Korea.

\section{Safety analysis}

Adverse events related to AF ablation also vary depending on the definition of major complications and study design. Recent meta-analysis of 11 randomized clinical trials comprising 785 patients reported 38 (4.8\%) major adverse events and 17 (2.1\%) pericardial complications. ${ }^{7}$ Survey data, including 85 centers and 20,825 procedures ( 16,309 patients), showed a $4.5 \%$ rate of major adverse events and $1.3 \%$ rate of cardiac tamponade. ${ }^{22}$ In our study, codes for pericardiocentesis and pericardial window operation were analyzed. These codes were assumed to represent significant pericardial complications. Pericardial complications were 
observed in 106 patients (2.8\%), which is a higher rate than was observed in clinical trials and survey analysis.

\section{Limitations}

There are potential limitations to our study. Since we retrieved administrative claims data for patients from a nationwide health insurance database, we could not determine the type or duration of $\mathrm{AF}$, other patient characteristics, and ablation strategy. Second, the definition of AF recurrence in our study is not based on ECG recordings. The decision not to retain sinus rhythm after recurrence of an index procedure was counted as freedom from atrial arrhythmia. Instead, antiarrhythmic drug use for atrial premature complexes or short runs of atrial tachyarrhythmia less than 30 seconds were counted as recurrence. Third, there may have been non-claimed ablation procedures, but their number is presumed to be negligible in South Korea. Regarding safety, important complications such as atrio-esophageal fistula and hospital readmission due to procedure-related complications were not analyzed. Although analysis cane be performed using ICD codes, the code tends to be over-listed for the convenience of reimbursement. Therefore, we considered ICD codes unreliable for analysis of significant complications related to AF ablation in South Korea.

\section{Conclusion}

In the present study, the recurrence rate of catheter ablation for drug-refractory AF in the Korean population using the HIRA database was $61.1 \%$. Patients over 65 years old had a higher recurrence rate than those under 65 years. Overall recurrence did not vary with respect to sex. Repeat ablation was more frequent in men and younger patients.

\section{Conflict of interest}

The authors report no relationship that could be construed as a conflict of interest

\section{References}

1) Kirchhof P, Benussi S, Kotecha D, Ahlsson A, Atar D, Casadei B,
Castella M, Diener HC, Heidbuchel H, Hendriks J, Hindricks G, Manolis AS, Oldgren J, Popescu BA, Schotten U, Van Putte B, Vardas P, Agewall S, Camm J, Baron Esquivias G, Budts W, Carerj S, Casselman F, Coca A, De Caterina R, Deftereos S, Dobrev D, Ferro JM, Filippatos G, Fitzsimons D, Gorenek B, Guenoun M, Hohnloser SH, Kolh P, Lip GY, Manolis A, McMurray J, Ponikowski P, Rosenhek R, Ruschitzka F, Savelieva I, Sharma S, Suwalski P, Tamargo JL, Taylor CJ, Van Gelder IC, Voors AA, Windecker S, Zamorano JL, Zeppenfeld K. 2016 ESC Guidelines for the management of atrial fibrillation developed in collaboration with EACTS. Europace. 2016;18:1609-1678.

2) January CT, Wann LS, Alpert JS, Calkins H, Cigarroa JE, Cleveland JC, Jr., Conti JB, Ellinor PT, Ezekowitz MD, Field ME, Murray KT, Sacco RL, Stevenson WG, Tchou PJ, Tracy CM, Yancy CW, American College of Cardiology/American Heart Association Task Force on Practice G. 2014 AHA/ACC/HRS guideline for the management of patients with atrial fibrillation: a report of the American College of Cardiology/American Heart Association Task Force on practice guidelines and the Heart Rhythm Society. J Am Coll Cardiol. 2014;64:e1-76.

3) Seo GH, Lee YK, Ha YC. Risk of hip fractures in men with alphablockers: a nationwide study base on claim registry. J Bone Metab. 2015;22:29-32.

4) Nyong J, Amit G, Adler AJ, Owolabi OO, Perel P, Prieto-Merino D, Lambiase P, Casas JP, Morillo CA. Efficacy and safety of ablation for people with non-paroxysmal atrial fibrillation. Cochrane Database Syst Rev. 2016;11:CD012088.

5) Morillo CA, Verma A, Connolly SJ, Kuck KH, Nair GM, Champagne J, Sterns LD, Beresh H, Healey JS, Natale A, Investigators R-. Radiofrequency ablation vs antiarrhythmic drugs as first-line treatment of paroxysmal atrial fibrillation (RAAFT-2): a randomized trial. JAMA. 2014;311:692-700.

6) Cosedis Nielsen J, Johannessen A, Raatikainen P, Hindricks G, Walfridsson H, Kongstad O, Pehrson S, Englund A, Hartikainen J, Mortensen LS, Hansen PS. Radiofrequency ablation as initial therapy in paroxysmal atrial fibrillation. $N$ Engl J Med. 2012;367:1587-1595.

7) Khan AR, Khan S, Sheikh MA, Khuder S, Grubb B, Moukarbel GV. Catheter ablation and antiarrhythmic drug therapy as first- or second-line therapy in the management of atrial fibrillation: systematic review and meta-analysis. Circ Arrhythm Electrophysiol. 2014;7:853-860. 
8) Ganesan AN, Shipp NJ, Brooks AG, Kuklik P, Lau DH, Lim HS, Sullivan T, Roberts-Thomson KC, Sanders P. Long-term outcomes of catheter ablation of atrial fibrillation: a systematic review and meta-analysis. J Am Heart Assoc. 2013;2:e004549.

9) Bertaglia E, Senatore G, De Michieli L, De Simone A, Amellone C, Ferretto S, La Rocca V, Giuggia M, Corrado D, Zoppo F, Stabile G. Twelve-year follow-up of catheter ablation for atrial fibrillation: A prospective, multicenter, randomized study. Heart Rhythm. 2016;14:486-492.

10) Haissaguerre M, Jais P, Shah DC, Garrigue S, Takahashi A, Lavergne T, Hocini M, Peng JT, Roudaut R, Clementy J. Electrophysiological end point for catheter ablation of atrial fibrillation initiated from multiple pulmonary venous foci. Circulation. 2000;101:1409-1417.

11) Kuck KH, Hoffmann BA, Ernst S, Wegscheider K, Treszl A, Metzner A, Eckardt L, Lewalter T, Breithardt G, Willems S, Gap AFAI. Impact of Complete Versus Incomplete Circumferential Lines Around the Pulmonary Veins During Catheter Ablation of Paroxysmal Atrial Fibrillation: Results From the Gap-Atrial Fibrillation-German Atrial Fibrillation Competence Network 1 Trial. Circ Arrhythm Electrophysiol. 2016;9:e003337.

12) Verma A, Jiang CY, Betts TR, Chen J, Deisenhofer I, Mantovan R, Macle L, Morillo CA, Haverkamp W, Weerasooriya R, Albenque JP, Nardi S, Menardi E, Novak P, Sanders P, Investigators SAI. Approaches to catheter ablation for persistent atrial fibrillation. $N$ Engl J Med. 2015;372:1812-1822.

13) Dong JZ, Sang CH, Yu RH, Long DY, Tang RB, Jiang CX, Ning M, Liu N, Liu XP, Du X, Tse HF, Ma CS. Prospective randomized comparison between a fixed '2C3L' approach vs. stepwise approach for catheter ablation of persistent atrial fibrillation. Europace. 2015;17:1798-1806.

14) Scott PA, Silberbauer J, Murgatroyd FD. The impact of adjunctive complex fractionated atrial electrogram ablation and linear lesions on outcomes in persistent atrial fibrillation: a meta-analysis. Europace. 2016;18:359-367.

15) Calkins H, Kuck KH, Cappato R, Brugada J, Camm AJ, Chen SA, Crijns HJ, Damiano RJ, Jr., Davies DW, DiMarco J, Edgerton J, Ellenbogen K, Ezekowitz MD, Haines DE, Haissaguerre M, Hindricks G, Iesaka Y, Jackman W, Jalife J, Jais P, Kalman J, Keane D, Kim YH, Kirchhof P, Klein G, Kottkamp H, Kumagai K, Lindsay BD, Mansour M, Marchlinski FE, McCarthy PM, Mont JL, Morady F, Nademanee K, Nakagawa H, Natale A, Nattel S,
Packer DL, Pappone C, Prystowsky E, Raviele A, Reddy V, Ruskin JN, Shemin RJ, Tsao HM, Wilber D. 2012 HRS/EHRA/ECAS expert consensus statement on catheter and surgical ablation of atrial fibrillation: recommendations for patient selection, procedural techniques, patient management and follow-up, definitions, endpoints, and research trial design. J Interv Card Electrophysiol. 2012;33:171-257.

16) Van Brabandt H, Neyt M, Devos C. Effectiveness of catheter ablation of atrial fibrillation in Belgian practice: a cohort analysis on administrative data. Europace. 2013;15:663-668.

17) Akoum N, Daccarett M, McGann C, Segerson N, Vergara G, Kuppahally S, Badger T, Burgon N, Haslam T, Kholmovski E, Macleod R, Marrouche N. Atrial fibrosis helps select the appropriate patient and strategy in catheter ablation of atrial fibrillation: a DE-MRI guided approach. J Cardiovasc Electrophysiol. 2011;22:16-22.

18) McCready JW, Smedley T, Lambiase PD, Ahsan SY, Segal OR, Rowland E, Lowe MD, Chow AW. Predictors of recurrence following radiofrequency ablation for persistent atrial fibrillation. Europace. 2011;13:355-361.

19) Berruezo A, Tamborero D, Mont L, Benito B, Tolosana JM, Sitges M, Vidal B, Arriagada G, Mendez F, Matiello M, Molina I, Brugada J. Pre-procedural predictors of atrial fibrillation recurrence after circumferential pulmonary vein ablation. Eur Heart $J$. 2007;28:836-841.

20) Zhang XD, Gu J, Jiang WF, Zhao L, Wang YL, Liu YG, Zhou L, $\mathrm{Gu}$ JN, Wu SH, Xu K, Liu X. The impact of age on the efficacy and safety of catheter ablation for long-standing persistent atrial fibrillation. Int J Cardiol. 2013;168:2693-2698.

21) Takigawa M, Kuwahara T, Takahashi A, Watari Y, Okubo K, Takahashi Y, Takagi K, Kuroda S, Osaka Y, Kawaguchi N, Yamao K, Nakashima E, Sugiyama T, Akiyama D, Kamiishi T, Kimura S, Hikita H, Hirao K, Isobe M. Differences in catheter ablation of paroxysmal atrial fibrillation between males and females. Int J Cardiol. 2013;168:1984-1991.

22) Cappato R, Calkins H, Chen SA, Davies W, Iesaka Y, Kalman J, Kim YH, Klein G, Natale A, Packer D, Skanes A, Ambrogi F, Biganzoli E. Updated worldwide survey on the methods, efficacy, and safety of catheter ablation for human atrial fibrillation. Circ Arrhythm Electrophysiol. 2010;3:32-38. 